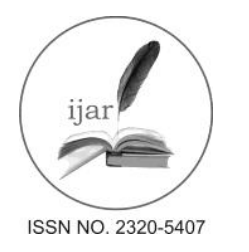

Journal homepage: http://www.journalijar.com
Journal DOI: 10.21474/IJAR01

INTERNATIONAL JOURNAL

OF ADVANCED RESEARCH

RESEARCH ARTICLE

\title{
MORBIDITY AND MORTALITY PATTERNS AMONG ADMITTED PATIENTS WITH DIABETES : A HOSPITAL BASED STUDY FROM NORTH INDIA.
}

\author{
Dr. Henna Naqash ${ }^{1}$, Prof. Gazanfar $\mathrm{Ali}^{2}$, Dr. Mohammad Hayat Bhat ${ }^{3}$. \\ 1. Senior Resident at Deptt. of General Medicine, GMC, Srinagar. \\ 2. Ex HOD, Deptt. of General Medicine, GMC, Srinagar. \\ 3. Lecturer, Deptt. of General Medicine, GMC, Srinagar. \\ Study conducted at SMHS Hospital, Associated hospital of GMC, Srinagar, India.
}

\section{Manuscript Info}

\section{Manuscript History:}

Received: 19 March 2016

Final Accepted: 19 April 2016

Published Online: May 2016

Key words:

Diabetes mellitus; hypertension; gestational diabetes; mortality.

*Corresponding Author

Dr. Henna Naqash.

\begin{abstract}
This study helps us to find the morbidity \& mortality patterns in patients with diabetes admitted in a tertiary care hospital in a developing country and confers information about their distribution among males \& females of different age groups, their relationship with concurrent diseases, obesity and the effect of various treatment modalities on the morbidity \& mortality. The objective is to find the morbidity and mortality patterns in people with diabetes admitted to a tertiary care hospital associated with Government Medical College Srinagar, in India.

Methods: In this prospective study, all patients with diabetes who were admitted to Sri Maharaja Hari Singh hospital [SMHS] (associated hospital of Government Medical College, Srinagar) over a period of 19 months were studied for diabetes-related complications.

Results: The most common morbidity among patients with diabetes admitted in this hospital was infection $(47.54 \%)$ followed by strokes $(9.09 \%)$. The most common cause of death in patients with diabetes was again infections $(60.34 \%)$, followed by strokes $(18.96 \%)$ and renal failure $(17.24 \%)$. Among admitted patients with diabetes, type 2 diabetes was the predominant type (95.2\%).6.4\% of these patients were obese. Maximum admissions were for infections $(47.5 \%)$, followed by Diabetic Ketoacidosis (10.64\%) and hypoglycaemia (7.87\%). Among complications, 52\% had neuropathy, 50\% had diabetic retinopathy, $27.2 \%$ had nephropathy and $4.9 \%$ had disease of coronaries.Major metabolic complications were Diabetic Ketoacidosis (3.42\%), Hypoglycemia (2.53\%) and Hyperglycemic Hyperosmolar state(HHS) (1.93\%). $8.64 \%$ among admitted patients died.12.06\% died of myocardial infarction and $5.1 \%$ died of hypoglycemia.

Conclusions:The most common morbidities in patients admitted with diabetes in this tertiary care hospital in a developing country are infections and strokes and the most common etiology for deaths is again infections followed by strokes and renal failure.
\end{abstract}

\section{Introduction:-}

Diabetes mellitus is a group of diseases marked by high levels of blood glucose resulting in defects in insulin production, insulin action ,or both. Diabetes mellitus has been known to the physicians of ancient times, passing of frequent and large quantity of urine was recorded in Papyrus Ebers, an Egyptian medical journal already old in times of Moses [1].African Americans, Hispanic/Latino Americans, American Indians, some Asian Americans \& native Hawaiians or other Pacific Islanders are at particularly high risk for type 2 diabetes \& its complications [2]. Undiagnosed T2DM is common, with an estimated lag of 5 to 7 years between the onset of diabetes \& diagnosis [3],[4],[5]. Globally, the number of people with diabetes is expected to rise from the current estimate of 285 million 
in 2010 to 438 million in 2030. T2DM has become one of the world's most important public health problems. Type 2 diabetes mellitus is the predominant form of diabetes worldwide, accounting for $90 \%$ of cases globally [6],[7]. One of the greatest relative increase in diabetes prevalence over the next 20 years is projected to occur in Africa. As per the National Diabetes Statistics Report, 2014(the most recent comprehensive assessment of the impact of diabetes in the United States, jointly produced by the CDC, NIH, ADA, and other organizations), in 2012, 29.1 million Americans, or $9.3 \%$ of the population, had diabetes. 1.4 million Americans are diagnosed with diabetes every year. Diabetes remains the 7th leading cause of death in the United States in 2010, Diabetes may be underreported as a cause of death. Studies have found that only about $35 \%$ to $40 \%$ of people with diabetes who died had diabetes listed anywhere on the death certificate and about $10 \%$ to $15 \%$ had it listed as the underlying cause of death. In 20092012, of adults aged 18 years or older with diagnosed diabetes, $71 \%$ had blood pressure greater than or equal to $140 / 90 \mathrm{mmHg}$ or used prescription medications to lower high blood pressure .Diabetes was listed as the primary cause of kidney failure in $44 \%$ of all new cases in 2011.About $60 \%$ of non-traumatic lower-limb amputations among people aged 20 years or older occur in people with diagnosed diabetes. In India, the prevalence \& incidence of diabetes mellitus is also increasing at a very rapid pace \& there are reports that the rising incidence of diabetes mellitus in India has given this developing country the dubious distinction of being the "Diabetes Capital of the world"[8].WHO predicts that developing countries will bear the brunt of this epidemic in the $21^{\text {st }}$ century, with $80 \%$ of all new cases of diabetes expected to appear in the developing countries by 2020 [9].

Criteria for the diagnosis of diabetes are shown in table 1.

Classification of diabetes:-

Type 1 diabetes (T1DM) usually strikes children \& young adults, or the disease onset can occur at any age. In adults, type 1 diabetes mellitus accounts for approximately 5\% of all diagnosed cases of diabetes. An expert committee of the American Diabetes Association, has recommended dividing T1DM into type 1A (immune mediated) \& type 1B (other forms of diabetes with severe insulin deficiency) [11].

Type 2 diabetes (T2DM) usually begins as insulin resistance, undiagnosed T2DM is common, with an estimated lag of 5 to 7 years between the onset of diabetes \& diagnosis [4],[5],[12].Genetically, T2DM consists of monogenic $\&$ polygenic forms [13],[14].

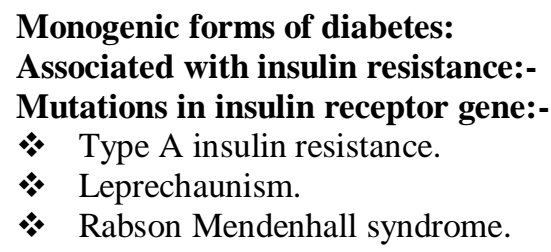

Lipoatrophic diabetes:-

Mutations in PPAR Y gene:-

Associated with defective insulin secretion:-

* Mutation in the insulin or proinsulin genes

* Mitochondrial gene mutations

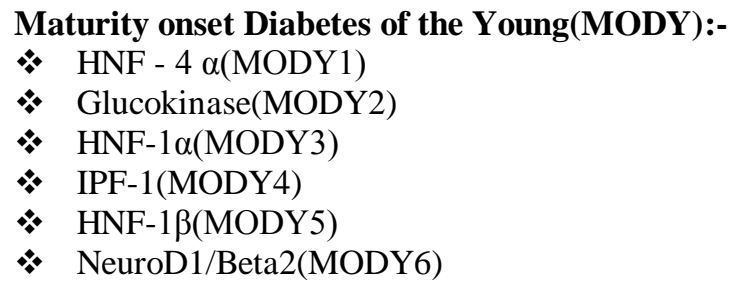

Gestational diabetes is a form of glucose intolerance diagnosed during pregnancy. Pregnancy is normally attended by progressive insulin resistance that begins near mid-pregnancy and progresses through the third trimester to levels that approximate the insulin resistance seen in individuals with type 2 diabetes. The insulin resistance appears to result from a combination of increased maternal adiposity and the insulin-desensitizing effects of hormonal products 
of the placenta. Robust plasticity of $\beta$ cell function in the face of progressive insulin resistance is the hallmark of normal glucose regulation during pregnancy [15].

Other types of diabetes result from specific genetic conditions, surgery, medications, infections, secondary to pancreatic disease, \& other illnesses. Such types of diabetes account for $1 \%$ to $5 \%$ of all diagnosed cases [18].

The association of obesity with T2DM has been recognised for decades. A close association between obesity $\&$ insulin resistance is seen in all ethnic groups $\&$ is found across the full range of body weights, across all ages $\&$ in both sexes [16],[17],[19].A constellation of metabolic derangements that are often seen in patients with insulin resistance \& T2DM are individually associated with an increased risk of cardiovascular disease : hypertension, obesity, non- insulin dependent diabetes mellitus (NIDDM), dyslipidemia, \& atherosclerotic cardiovascular disease; or "the deadly quartet"[20],[21].Hyperglycemia is a primary factor in the development of complications of diabetes, \& decreases in average blood glucose have a profound effect to prevent complications in both T1DM \& T2DM [22].

\section{There are various complications of diabetes like:-}

Heart disease \& stroke:- Heart disease death rates in diabetics are about 2 to 4 times higher than non diabetics \& the risk for stroke is 2 to 4 times higher in people with diabetes [23],[24].The Framingham Study showed a twofold to threefold elevation in the risk of clinically evident atherosclerotic disease in patients with T2DM compared to those without diabetes [25].

Hypertension:- Hypertension is very common in population with diabetes as compared to non diabetics [26].

Kidney disease:- Diabetes is the leading cause of kidney failure accounting for $44 \%$ of all new cases of kidney failure [27].In the United Kingdom Prospective Diabetes Study (UKPDS), a reduction in BP from 154 to $144 \mathrm{mmHg}$ was associated with a $30 \%$ reduction in microalbuminuria [28].

Nervous system disease:- About 60 to $70 \%$ of people with diabetes have mild to severe form of nervous system damage including peripheral neuropathies, carpal tunnel syndrome \& severe sensorineuropathy resulting in lower extremity amputations \& entrapment neuropathies [29],[31].

Blindness \& retinopathy:- Diabetes is the leading cause of blindness between ages of 20 to 65 years [30].

Amputations:- More than $60 \%$ of lower limb amputations occur in patients with diabetes [32].

Dental diseases:- Periodontal gum disease is more common in people with diabetes. It is twice more common in diabetics than non diabetics. About one-third of people with diabetes have severe periodontal disease consisting of loss of attachment of gums to teeth [33].

Metabolic complications:- like diabetic ketoacidosis, hyperosmolar coma \& hypoglycemia are common in diabetics [34].Diabetic ketoacidosis is a life threatening condition in which severe insulin deficiency leads to hyperglycemia, excessive lipolysis, \& unrestrained fatty acid oxidation, producing the ketone bodies acetone, betahydroxy butyrate, \& acetoacetate. This results in metabolic acidosis, dehydration, \& deficits in fluid \& electrolytes.

\section{Hypoglycemia is classified as [35]:}

a) Severe..requiring assistance of another person to take corrective actions, with neurologic recovery following glucose administration without documenting low plasma glucose.

b) Documented symptomatic hypoglycaemia..typical symptoms with plasma glucose $<70 \mathrm{mg} / \mathrm{dL}$.

c) Asymptomatic hypoglycaemia..blood glucose $<70 \mathrm{mg} / \mathrm{dL}$ without typical symptoms.

d) Probable symptomatic hypoglycaemia..Typical symptoms likely caused by plasma glucose $<70 \mathrm{mg} / \mathrm{dL}$.

e) Pseudo-hypoglycemia..typical hypoglycaemia symptoms with plasma glucose $>70 \mathrm{mg} / \mathrm{dL}$.

Others:- Diabetics are more susceptible to many other illnesses, infections \& depression [37],[38].

\section{Classification of complications of diabetes:-}

Classification of retinopathy [39]is shown in Table 2.

Nephropathy is classified as:- 


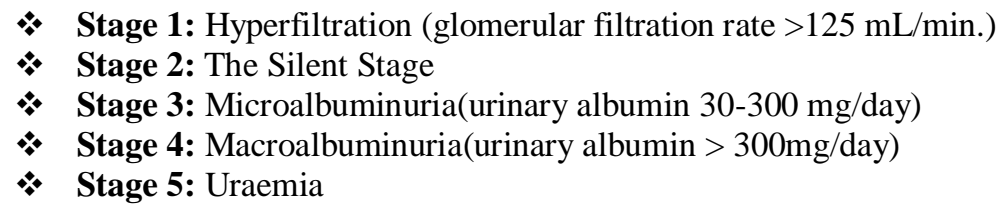

\section{Classification of neuropathy as per San Antonio Convention [40] is as follows:-} Subclinical neuropathy:-

Diffuse clinical neuropathy with distal symmetric sensorimotor \& autonomic syndromes.

\section{Focal syndromes:-}

Diabetic foot is classified according to Wagner or University of Texas criteria as shown in Tables 3 and 4 , respectively.

Multiple epidemiologic studies have suggested that there is an association between cardiovascular risk \& HbA1c, FPG \& 2 hr PP Glucose levels [36]. The various management strategies are lifestyle interventions, education of patients, Medical Nutrition Therapy (MNT), exercise, self monitoring of blood glucose and pharmacotherapy using oral hypoglycemic agents or insulin therapy.The American Diabetes Association (ADA) has advised certain glycemic targets in patients with diabetes. They are shown in Table 5.

\section{Materials And Methods:-}

Since the number of patients with diabetes mellitus has increased dramatically, \& there are few data on the rates of morbidity, serious complications \& mortality from the Government Medical College, Srinagar \& associated hospitals. No study has been carried out from this institute. To determine such rates of morbidity \& mortality, we have conducted this prospective study on admitted diabetic population.The study is hospital based. All patients with diabetes who were admitted to SMHS hospital, a tertiary care hospital, over a period of 19 months in various wards, both medical/surgical \& other wards, were studied for diabetes-related complications like heart disease \& stroke, hypertension, blindness \& retinopathy, kidney disease, neurologic disease, dermatological disease, diabetic foot/amputations, periodontal (gum) disease \& metabolic complications such as diabetic ketoacidosis \& hyperosmolar (non-ketotic) coma, hypoglycemia, infections \& psychiatric illnesses .

Complete clinical profile of these patients was recorded, which included -age $\quad$-sex $\quad$ duration of diabetes \& treatment $\quad$ residence $\quad$ general physical examination $\quad$ systemic examination.

The primary end-point of this study was to find the morbidity \& mortality in diabetics. The secondary end points were observed as differences of morbidity \& mortality in males \& females and the relationship of morbidity \& mortality with age. The patients were divided into three age groups: A. $<45$ years B. 45 to 60 years C. $>60$ years. The relationship of other concurrent diseases, obesity and various treatment modalities with morbidity $\&$ mortality patterns in patients with diabetes was studied. To determine the cause of death, the patients were divided into four groups Group A: single cause of death; Group B: two causes of death; Group C: three causes of death; Group D: four or more causes of death .

Data analysis:- The data was analysed statistically using Pearsons chi square test of association; wherever needed, Mann Whitney $\mathrm{u}-$ test and Chi Square test with Yates correction was applied. $\mathrm{p}$ - value of $<0.05$ was taken as significant.

\section{Results:-}

All patients with diabetes who were admitted to SMHS hospital over a period of 19 months were studied for diabetes-related complications. Among the admitted patients who expired, the most probable cause of death was also studied.

Age distribution of study subjects revealed maximum subjects in $60-80$ year age group \& minimum in upto 20 years of age.

About two - thirds of subjects $(60.05 \%)$ were females and one - third (39.94\%) were males. 
As depicted in Table 6, mean age among males was 59.26+13.8 (min14yrs,max 90yrs) which was slightly higher than among females that was $57.56+13.8$ (min $8 y r s, \max 90 y r s)$.

$55.89 \%$ of total admitted patients were from rural and $44.11 \%$ from urban areas as shown in Table 7.

Table 8 shows the percentage of different types of diabetes among studied patients. The bulk of patients were type 2 diabetics $(95.23 \%)$ and a minority had type 1 diabetes $(1.94 \%)$, followed by secondary forms of diabetes (1.79\%) and gestational diabetes in the rest (1.04\%).According to IADPSG (International Association of Diabetes and Pregnancy Study Group) and American Diabetes Association guidelines, gestational diabetes is diagnosed only if the glucose intolerance is identified during pregnancy AND the woman does not qualify for pre-existing (overt) diabetes. Criteria for overt diabetes in pregnancy are HbA1c $>6.5 \%$, fasting blood glucose level $>126 \mathrm{mg} / \mathrm{dL}$, or random glucose level $>200 \mathrm{mg} / \mathrm{dL}$. The diagnostic criteria for gestational diabetes in our patients were a single abnormal value after taking $75 \mathrm{~g}$ oral glucose. The values as per ADA are fasting glucose $>92 \mathrm{mg} / \mathrm{dL}$, post $1 \mathrm{hour}$ glucose $>180 \mathrm{mg} / \mathrm{dL}$, and 2-hour post glucose $>153 \mathrm{mg} / \mathrm{dL}$.

About three-fourths of patients were having 1-10 years duration of diabetes.15\% of the patients had diabetes for more than 10 years. Rest were newly detected or had diabetes for less than 12 months. Results are shown in Table 9.

Maximum number of admissions were for infections, followed by those for glycemic control.9.09 \% patients were admitted with strokes. Besides these indications, major admissions were with surgical problems, followed by myocardial infarction, COPD exacerbations and renal failure. The percentage of different reasons for admission of diabetics is shown in Table 10.

As shown in Table 11, maximum number of admitted patients with diabetes were on insulin therapy, followed by OHAs. One- fourth of patients were switched over from one form of therapy to another and only $2.38 \%$ patients were on combination therapy of insulin and OHAs.

Table 12 and Figure 1 depicts the distribution of morbidities among diabetic patients. Major morbidities among admitted diabetics were hypertension in $42.62 \%$, and high risk feet in $62 \%$ patients. $15 \%$ patients had recurrent boils and $13 \%$ had non healing ulcers. More than half of admitted females had a history of pruritus vulvae. Hypertension was diagnosed in these patients on the basis of BP> 140/90mmHg or patient already on BP lowering drugs. Patients with high risk feet had cracks, sores in feet with pressure spots, calluses, past ulcers or dirty, infected feet with loss of sensations or proprioception.

23 patients were admitted with diabetic foot and 8 out of those patients underwent amputations.

Psychiatric illness was present in 57 patients (8.49\%) in the form of depression, bipolar affective disorder or schizophrenia.

Malignancies were present in $30(4.47 \%)$ patients and involved breast in 5, gall bladder in 4 , lung in 3 , cecum or colon in 3 , larynx in 2 , thyroid in 2 , stomach in 2 , brain ( high grade glioma) in 1 , blood (chronic lymphocytic leukemia) in 1 , urinary bladder in 1 , pancreas in 1 , esophagus in 1 , kidney in 1 , prostate plus bladder in 1 , and with unknown primary in 1 patient.

Overall, 6.4\% among admitted patients and 5.17\% among mortalities were obese as shown in Table 13 . Obesity was diagnosed by a body mass index greater than or equal to $30 \mathrm{~kg} / \mathrm{m}^{2}$.

Figure 2 shows that half of all patients had diabetic retinopathy, more than half had neuropathy (either clinical or nerve conduction study based). Nephropathy was found in about one - fourth of all patients and $4.9 \%$ had disease of coronaries.Coronary Artery Disease (CAD) was diagnosed in patients who were presently admitted with myocardial infarction or ischemia, alresdy diagnosed as ischemic heart disease in past (clinical or angiographic).

As the level of HbA1c increases, the proportion of retinopathy subjects also increases. Notice that the Pearsons Chi Square test is highly significant for this relation with p-value of $<0.001$.It tests the hypothesis that the percentage of subjects with retinopathy shows marked increase with the increase in HbAlc.Similarly,it was found that there is a significant relation between rising levels of HbA1c and neuropathy as well as nephropathy .The relation between 
rising $\mathrm{HbA} 1 \mathrm{c}$ levels and $\mathrm{CAD}$ was found to be insignificant.HbA1c was determined in protocol with the assays calibrated against the DCCT (Diabetes Control and Complications Trial) A1c assay. Results are shown in Figure 3.

There was found to be a highly significant association between increasing duration of diabetes and retinopathy, neuropathy and nephropathy. However, coronary heart disease had an insignificant association with the duration of diabetes. Results are revealed in Figure 4.

There is a significant association between treatment modality used and development of diabetic ketoacidosis. However no significant association was found between treatment type and HHS or hypoglycemia. See Table 14.

More than half of patients died because of infections. Next major cause was strokes followed by renal failure and myocardial infarction (See Figure 5).Mean age of men who died was 60.8 years and among females, it was 66.5 years. Maximum number of patients died of a single cause. See Table 15 and Figure 6.

Mean $\mathrm{HbAlc}$ level was highest in patients who died of infections (8.47) and lowest in those who died of hypoglycaemia (6.67).Hypoglycemia in our studied patients was documented symptomatic class .See Table 16 and Figure 7.

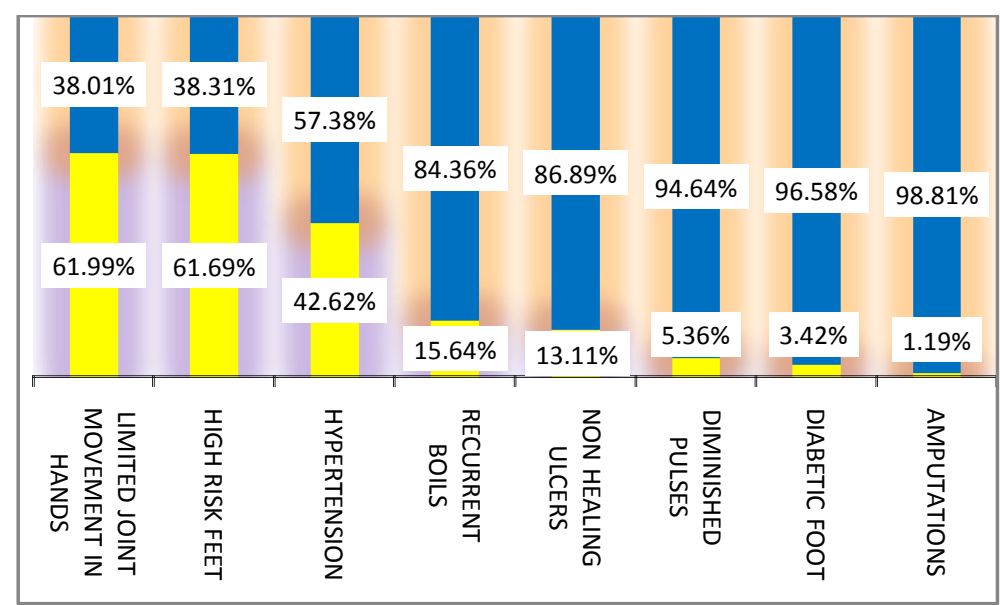

Figure 1:- Distribution of morbidities among study subjects.

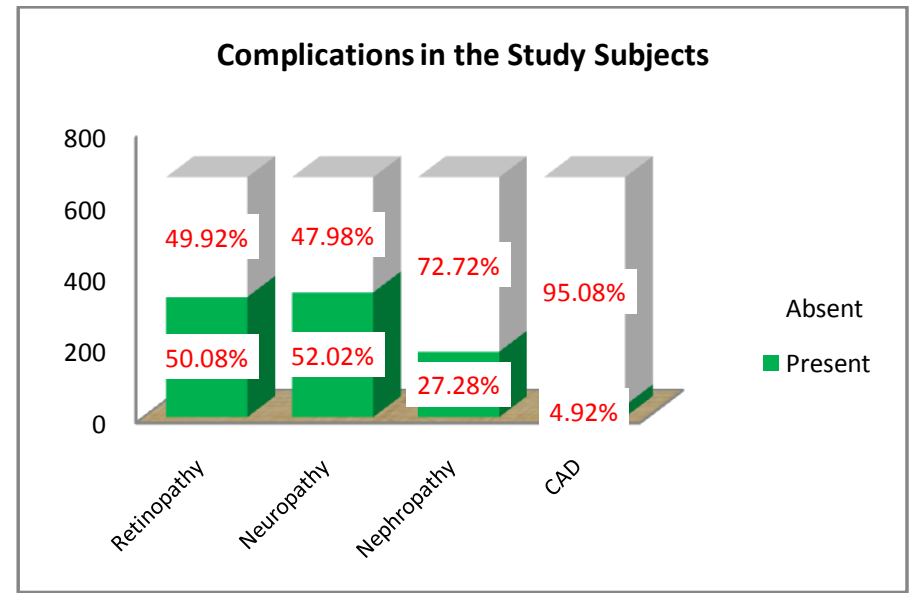

Figure 2:- Complications among study subjects. 


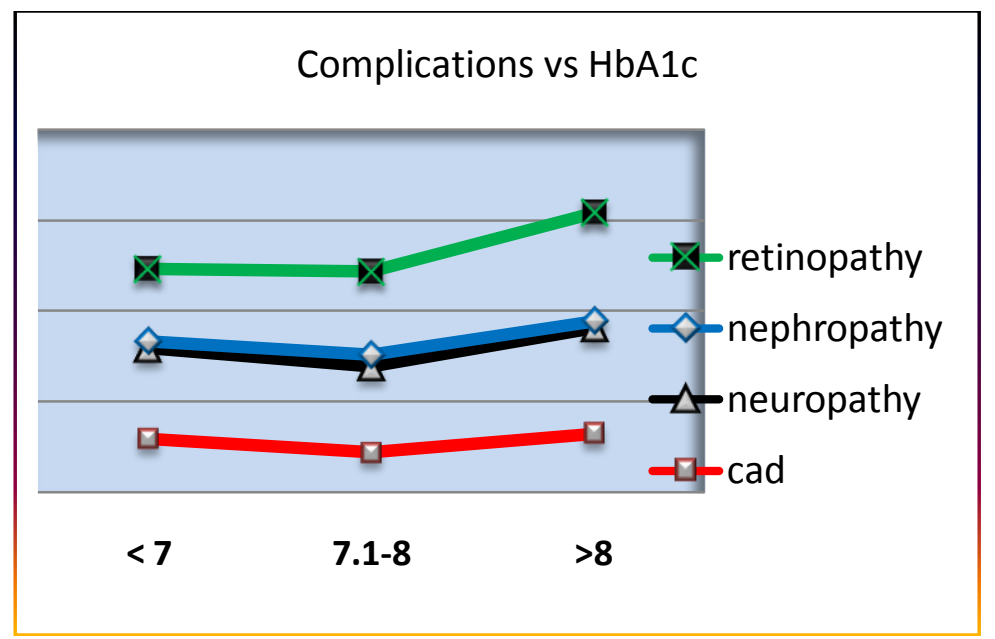

Figure 3:- Relation of complications with HbA1c level.

Complications vs Duration of diabetes

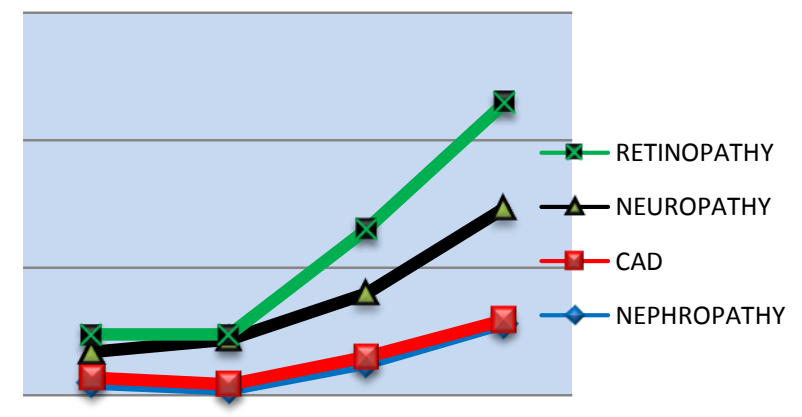

NEWLY MONTHS 1-10 YEARS $>10$ YEARS DETECTED

Figure 4:- Relation of complications with the duration of diabetes.

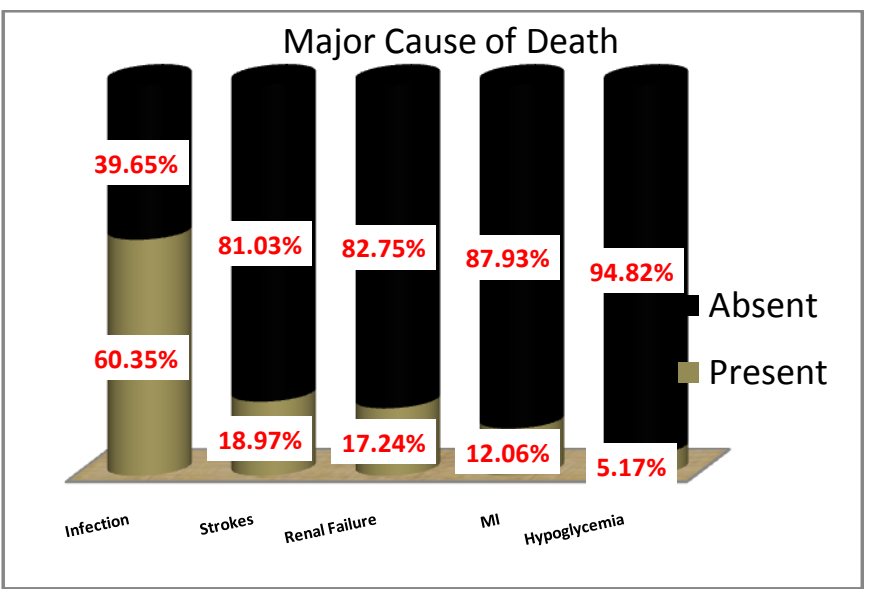

Figure 5:- Causes of mortality among diabetics. 


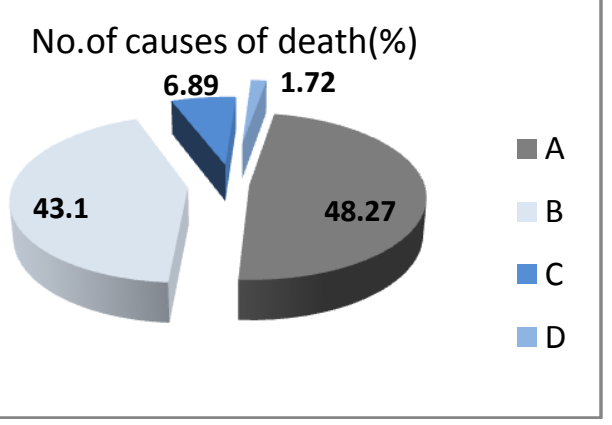

Figure 6:- Number of causes of death.

A : Single cause of death.

B : Two causes of death.

C: Three causes of death.

D: Four or more causes of death.

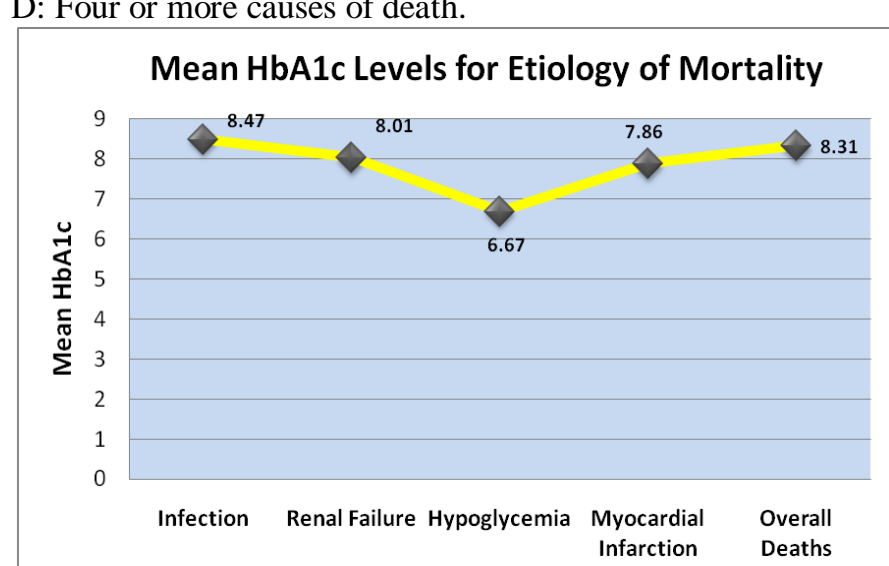

Figure 7:- Mean HbA1c level among mortalities.

Table 1:- Criteria for diagnosis of diabetes.

\begin{tabular}{|l|l|l|l|l|}
\hline Test & Normoglycemia (mg/dl) & IFG (mg/dl) & IGT (mg/dl) & Diabetes \\
\hline FPG & $<100$ & $100-125$ & & $\geq 126 \mathrm{mg} / \mathrm{dl}$ \\
\hline 2-hr PG & $<140$ & & $140-199$ & $\geq 200 \mathrm{mg} / \mathrm{dl}$ \\
\hline HbA1c & $<5.6 \%$ & & & $>6.5 \%$ \\
\hline Casual plasma glucose & & & & $\begin{array}{l}\geq 200 \mathrm{mg} / \mathrm{dl} \text { plus symptoms of } \\
\text { diabetes; or hyperglycaemic } \\
\text { crisis. }\end{array}$ \\
\hline
\end{tabular}

IFG : Impaired fasting glucose; IGT: impaired glucose tolerance.

Fasting is defined as no caloric intake for at least 8 hours.

Symptoms of diabetes include polyuria, polydipsia, polyphagia, weight loss.

Table 2:- Classification of retinopathy.

\begin{tabular}{|c|c|}
\hline International Classification Level & ETDRS Level \\
\hline No apparent retinopathy & Level 10:DR absent \\
\hline Mild NPDR & Level 20:very mild NPDR \\
\hline Moderate NPDR & Levels 35, 43, 47;moderate NPDR \\
\hline Severe NPDR & Levels 53A-E;severe to very severe NPDR \\
\hline PDR & $\begin{array}{l}\text { Levels } 61,65,71,75,81,85 ; \text { PDR,high risk } \\
\text { PDR,very severe or advanced PDR }\end{array}$ \\
\hline
\end{tabular}

ETDRS : Early Treatment Diabetic Retinopathy Study; NPDR : Non proliferative diabetic retinopathy; PDR Proliferative diabetic retinopathy.

Non proliferative diabetic retinopathy is characterised by retinal microaneurysms, occasional blot haemorrhages, hard exudates and one or two soft exudates. 
Proliferative diabetic retinopathy is characterised by new vessels on the optic disc or elsewhere on the retina, preretinal or vitreous haemorrhage or fibrous tissue proliferation.

Table 3:- Grading of diabetic foot as per Wagner classification.

\begin{tabular}{|l|l|}
\hline Grade & Description \\
\hline 0 & No ulcer, but high risk foot(e.g., deformity, callus, insensitivity \\
\hline 1 & Superficial full thickness ulcer \\
\hline 2 & Deeper ulcer, penetrating tendons, no bone involvement \\
\hline 3 & Deeper ulcer with bone involvement, osteitis \\
\hline 4 & Partial gangrene(e.g., toes, forefoot) \\
\hline 5 & Gangrene of whole foot \\
\hline
\end{tabular}

Table 4:- University of Texas classification of diabetic foot.

\begin{tabular}{|l|l|l|l|l|}
\hline Stage & Grade 0 & Grade 1 & Grade 2 & Grade3 \\
\hline A & $\begin{array}{l}\text { Preulcer or postulcer } \\
\text { lesion.No skin break }\end{array}$ & Superficial ulcer & $\begin{array}{l}\text { Deep ulcer to } \\
\text { tendon } \\
\text { capsule }\end{array}$ & Wound penetrating bone or joint \\
\hline B & +Infection & +Infection & +Infection & +Infection \\
\hline C & +Ischemia & +Ischemia & +Ischemia & +Ischemia \\
\hline D & +Infection \& Ischemia & $\begin{array}{l}\text { +Infection \& } \\
\text { Ischemia } \\
\text { +Infection \& }\end{array}$ & +Infection \& Ischemia \\
\hline
\end{tabular}

Table 5:- Glycemic targets in patients with diabetes.

\begin{tabular}{|l|l|l|}
\hline Parameter & Normal & ADA \\
\hline Premeal plasma glucose $(\mathrm{mg} / \mathrm{dl})$ & $<100$ & $70-130$ \\
\hline Postprandial plasma glucose $(\mathrm{mg} / \mathrm{dl})$ & $<140$ & $<180$ \\
\hline HbA1c & $4-6 \%$ & $<7 \%$ \\
\hline
\end{tabular}

Table 6:- Age and Gender Distribution of Study Subjects.

\begin{tabular}{|c|c|c|c|c|c|c|}
\hline \multirow{2}{*}{ Age (Years) } & \multicolumn{2}{|l|}{ Males } & \multicolumn{2}{|c|}{ Females } & \multicolumn{2}{|l|}{ Total } \\
\hline & $\mathrm{n}(268)$ & $\%(39.94)$ & $\mathrm{n}(403)$ & $\%(60.05)$ & $\mathrm{n}(671)$ & $\%$ \\
\hline$\leq 20$ & 4 & 1.49 & 8 & 1.98 & 12 & 1.78 \\
\hline $21-40$ & 24 & 8.95 & 43 & 10.66 & 67 & 9.98 \\
\hline $41-60$ & 117 & 43.65 & 192 & 47.64 & 309 & 46.05 \\
\hline $61-80$ & 118 & 44.02 & 153 & 37.96 & 271 & 40.38 \\
\hline$>80$ & 5 & 1.86 & 7 & 1.73 & 12 & 1.78 \\
\hline $\begin{array}{l}\text { Mean + SD } \\
(\text { Min;Max) }\end{array}$ & \multicolumn{2}{|c|}{$59.26+13.8(14,90)$} & \multicolumn{2}{|c|}{$57.56+13.8(8,90)$} & \multicolumn{2}{|c|}{$58.24+13.8(8,90)$} \\
\hline
\end{tabular}

Table 7:- Dwelling of the Study Subjects.

\begin{tabular}{|c|c|c|}
\hline Dwelling & No. of Patients & \% age \\
\hline Rural & 375 & 55.89 \\
\hline Urban & 296 & 44.11 \\
\hline Total & 671 & 100.0 \\
\hline
\end{tabular}

Table 8:- Type of diabetes in study subjects.

\begin{tabular}{|c|c|c|}
\hline Type of Diabetes & $\mathbf{n}$ & \% age \\
\hline Type-2 & 639 & 95.23 \\
\hline Type-1 & 13 & 1.94 \\
\hline Secondary & 12 & 1.79 \\
\hline Gestational & 07 & 1.04 \\
\hline Total & 671 & 100.0 \\
\hline
\end{tabular}


Table 9:- Duration of diabetes in patients.

\begin{tabular}{|c|c|c|}
\hline Duration & No. of patients & \%age \\
\hline Upto 1 year & 88 & 13.11 \\
\hline 1- 10 years & 481 & 71.68 \\
\hline >10years & 102 & 15.20 \\
\hline
\end{tabular}

Table 10:- Reasons for admission.

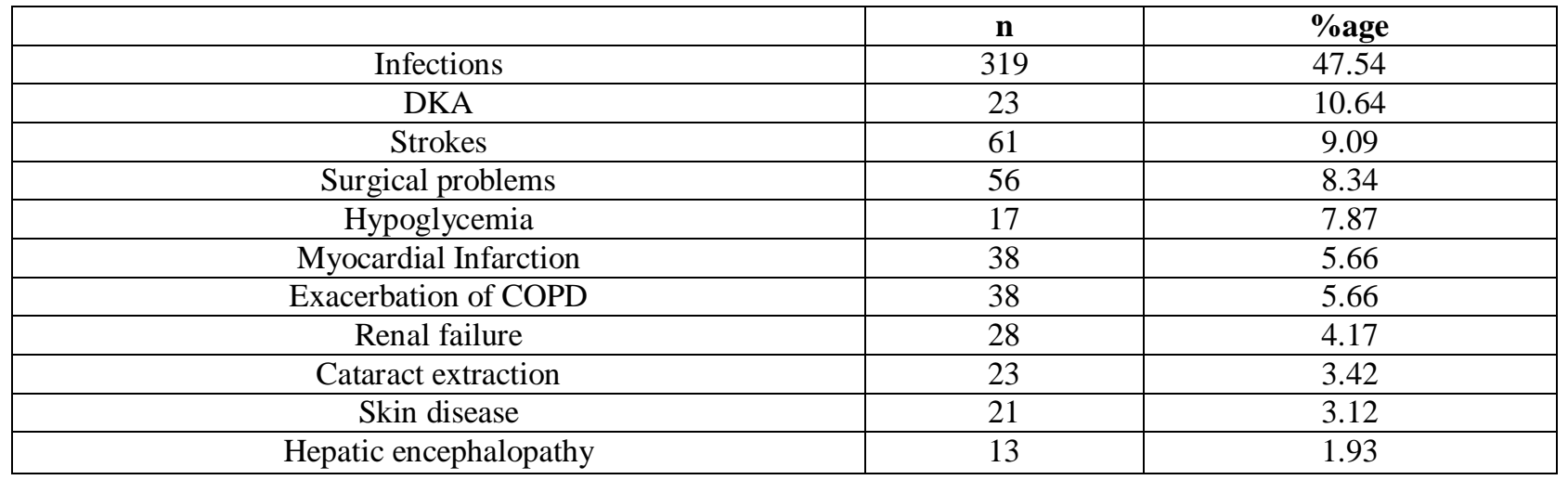

Table 11:- Treatment modalities among study subjects.

\begin{tabular}{|c|c|c|}
\hline DRUGS & $\mathbf{n}$ & \% \\
\hline Insulin & 284 & 29.33 \\
\hline OHAs & 200 & 25.81 \\
\hline OHAs $\rightarrow$ Insulin & 171 & 2.38 \\
\hline OHAs + Insulin & 16 & 100.0 \\
\hline Total & 671 & \\
\hline
\end{tabular}

Table 12:- Distribution of morbidities among study subjects.

\begin{tabular}{|c|c|c|}
\hline Morbidities & n age & 87.33 \\
\hline Osmotic Symptoms at onset & 586 & 61.99 \\
\hline Limited Joint Movement in hands & 416 & 61.69 \\
\hline High Risk Feet & 414 & 57.07 \\
\hline Pruritus Vulvae & 230 & 42.62 \\
\hline Hypertension & 286 & 22.05 \\
\hline Cataracts & 148 & 15.64 \\
\hline Recurrent Boils & 105 & $14 \%$ \\
\hline Gum disease & 94 & 13.11 \\
\hline Non Healing Ulcer & 88 & 5.36 \\
\hline Diminished Peripheral Pulses & 36 & 3.42 \\
\hline Asymptomatic & 23 & 3.42 \\
\hline Diabetic foot & 23 & 1.19 \\
\hline
\end{tabular}

Table 13:- Obesity among admitted patients with diabetes.

\begin{tabular}{|c|c|c|}
\hline & $\mathbf{n}$ & \%age \\
\hline \multicolumn{3}{|c|}{ Overall } \\
\hline Obese & 43 & 6.40 \\
\hline Non obese & 628 & 93.60 \\
\hline \multicolumn{3}{|c|}{ Mortality } \\
\hline Obese & 3 & 5.17 \\
\hline Non obese & 55 & 94.83 \\
\hline
\end{tabular}


Table 14:- Metabolic complications among study subjects.

\begin{tabular}{|c|c|c|c|c|c|c|}
\hline \multicolumn{2}{|l|}{ Complications } & \multicolumn{3}{|l|}{ Drugs } & \multirow[b]{2}{*}{ OHAs to Insulin } & \multirow[b]{2}{*}{$\mathrm{P}$ - value } \\
\hline & & OHAs & Insulin & OHAs + Insulin & & \\
\hline \multirow[t]{2}{*}{ DKA } & Present & 1 & 15 & 2 & 5 & \multirow[t]{2}{*}{0.007 (Sig) } \\
\hline & Absent & 199 & 269 & 14 & 166 & \\
\hline \multirow[t]{2}{*}{ HHS } & Present & 0 & 7 & 1 & 5 & \multirow[t]{2}{*}{$0.078(\mathrm{~ns})$} \\
\hline & Absent & 200 & 277 & 15 & 166 & \\
\hline \multirow[t]{2}{*}{ Hypoglycemia } & Present & 6 & 7 & 0 & 4 & \multirow[t]{2}{*}{$0.891(\mathrm{~ns})$} \\
\hline & Absent & 194 & 277 & 16 & 167 & \\
\hline
\end{tabular}

OHA :Oral hypoglycaemic agent; DKA: diabetic ketoacidosis; HHS :Hyperglycemic hyperosmolar state.

Table 15:- Mean ages among mortalities.

\begin{tabular}{|c|c|}
\hline & Mean+SD \\
\hline Overall & $63.79+12.02 \mathrm{SD}$ \\
\hline Males & $60.85+13.0$ \\
\hline Females & $66.53+10.51$ \\
\hline \multicolumn{2}{|l|}{ Death due to: } \\
\hline Infections & $63.47+12.54$ \\
\hline Strokes & $58.14+13.92$ \\
\hline Renal failure & $69.80+9.46$ \\
\hline Hypoglycemia & $65.0+13.22$ \\
\hline Myocardial infarction & $64.57+5.12$ \\
\hline
\end{tabular}

Table 16:- Mean HbA1c levels in studied patients.

\begin{tabular}{|c|c|c|c|}
\hline Characteristics & n & Min ; Max & Mean + SD \\
\hline Overall & 671 & $(5.6 ; 18.0)$ & $87+1.36$ \\
\hline \multicolumn{4}{|c|}{ Cause of Mortality } \\
\hline Infection & 35 & $(6.1 ; 15.0)$ & $8.47+1.69$ \\
\hline Renal Failure & 10 & $(6.2 ; 10.2)$ & $8.01+1.36$ \\
\hline Myocardial Infarction & 07 & $(6.8 ; 9.5)$ & $6.86+0.89$ \\
\hline Hypoglycemia & 03 & $(6.1 ; 7.1)$ & $8.67+0.51$ \\
\hline Overall Deaths & 58 & $(6.1 ; 15.0)$ & $8.31+1.53$ \\
\hline
\end{tabular}

\section{Discussion:-}

This study is hospital based carried out in SMHS Hospital on admitted patients with diabetes over a period of 19 months. The study was carried on a total of 671 patients out of whom $268(39.9 \%)$ were males and $403(60 \%)$ were females. The main findings of the study are:

1. the most common morbidity among diabetics admitted in this hospital is infection followed by strokes.

2. the most common cause of death in diabetics is again infections, followed by strokes and renal failure.

About $40 \%$ of patients were males and $60 \%$ were females. The mean age of admitted patients was 58.2 years (59.2 years in males and 57.5 years in females).Maximum number of subjects were in $60-80$ year age group \& minimum in upto 20 years of age. Minimum age among study subjects was 8 years and maximum was 90 years. These results are consistent with other published reports [41],[42],[43],[44],[45],[46],[47]. There was a predominance of diabetics from rural areas $(55.89 \%)$ as compared to urban areas $(44.11 \%)$. Similar findings have been reported by JCN Mbanya et al [44] but are in contrast to findings of Daina Lucia et al [41] and B.B.Tripathy [48] who showed a predominance of diabetics from urban areas. The bulk of patients were type 2 diabetics (95.2\%) and a minority had type 1 diabetes (1.9\%), followed by secondary forms of diabetes (1.7\%) and gestational diabetes (1\%) in the rest, these observations are similar with other published studies [41],[48]. Overall 6.4\% admitted patients were obese. Similar results were reported by Raoul M Kamadjeu et al [49]. Maximum number of patients (about three-fourths) were having 1-10 years duration of diabetes.15\% of the patients had diabetes for more than 10 years. Rest were newly detected or had diabetes for less than 12 months. 
Maximum number of admissions were for infections (47.5\%). Mortality and morbidity in our diabetic population is higher from both pyogenic and tubercular infections as reported previously also [48].Commonest infections found in our patients were those involving the urinary tract $(23.5 \%)$ followed by pneumonias $(17.5 \%) .10 .64 \%$ admissions were because of Diabetic Ketoacidosis. In the least developed countries, diabetic ketoacidosis continues to be the commonest emergency in diabetes, often precipitated by infections, and its contribution to mortality rate is $3.4 \%$ in India [50],[51]. $9.09 \%$ patients were admitted with strokes (36\% ischemic and 64\% haemorrhagic).Besides these indications, major admissions were with surgical problems $(8.34 \%)$, followed by myocardial infarction (5.6\%),COPD exacerbations (5.6\%) and renal failure (4.1\%).These observations are not consistent with findings reported by Alain G Bertoni et al [52] who reported that the incidence of ischemic heart disease \& stroke was higher than the incidence of all other diabetes related morbidities. Cardiovascular complications were a leading cause for morbidity as shown by M.Angelyn Bethel et al [53] and other studies [47],[54],[55],however,these were seen only in $53.28 \%$ of patients in the present study. Majority of admitted diabetics were on insulin therapy (42.3\%), followed by OHAs (29.8\%).One- fourth of patients were switched over from one form of therapy to another and only $2.38 \%$ patients were on combination therapy of insulin and OHAs. Type of treatment correlates with micro-angiopathic complications as shown by MMS Ahuja et al [56]. Major morbidities among admitted diabetics were hypertension in $42.62 \%$, and high risk feet in $62 \%$ patients. $15 \%$ patients had recurrent boils and $13 \%$ had non healing ulcers among others as shown in Table 12 .

Half of all patients (50\%) had diabetic retinopathy in the present study, which is not same as findings of Jean Claude Mbanya et al [46] who reported only 18\% diabetics with retinopathy and Eugene Sobngwi et al [46] also observed background retinopathy in only $18 \%$ and cataract in $14 \%$ and these were the most common eye complications in diabetics as reported in other studies [30],[45],[57] also.In our study, 20\% of patients had cataract. In the present study,more than half (52\%) had neuropathy, that was consistent with the study of Jean Claude Mbanya et al [46] who reported neuropathy in 48\% and the study by Upinder K Dhand [58] who showed that $60 \%$ of peripheral neuropathy was due to diabetes, however, the results were not same as reported by Pradeepa $R$ et al [59] where only $26.1 \%$ had diabetic neuropathy. Symptomatic polyneuropathy appears to be more common and autonomic neuropathy less dangerous among our patients compared to those in the West as reported by P L Wahi [60]. Nephropathy in the form of albuminuria was found in about one - fourth of all patients (27.2\%). In the European Diabetes Prospective Complications Study, the cumulative incidence of microalbuminuria in patients with type 1 diabetes was $\sim 12 \%$ during a period of 7 years [61],[62]. In the UKPDS, the incidence of microalbuminuria was $2 \%$ per year in patients with type 2 diabetes, and the 10-year prevalence after diagnosis was $25 \%$ [10],[61]. As per the National Diabetes Fact Sheet, 2011 [63], diabetes is the leading cause of kidney failure, accounting for 44\% of all new cases of kidney failure in 2008. A recent population based study by Mohan et al [64] reported that the prevalence of overt nephropathy was 2.2 per cent in Indians while microalbuminuria was present in 26.9 percent. Nearly $30 \%$ of patients have proteinuria after 20 years of type 2 diabetes as observed by Krolewski AS and Warram JH [65]. $4.9 \%$ had disease of coronaries (patient either already diagnosed or presently admitted with myocardial ischemic insult) in the present study which is in confirmity with other studies.PL Wahiet et al [60] reported IHD to be present in $15 \%$ of diabetic population. Andre Pascal Kengne et al [66] showed that coronary heart disease may affect $5-8 \%$ of type 2 diabetic patients. The increased vulnerability of South Asians to coronary artery disease has also been reported by Rajendra Pradeepa et al [67] and others [47],[54],[55].The INTERHEART study conducted in 52 countries demonstrated that over $90 \%$ of the population-attributable risk of acute myocardial infarction were accounted for by nine modifiable risk factors, which included diabetes [50].

Mean $\mathrm{HbA1c}$ level in study population was 8.07+ 1.36. A significant relation between increasing HbA1c levels and risk of complications namely retinopathy ( $\mathrm{p}$-value $<0.001$ ), neuropathy (p-value=0.038) and nephropathy (pvalue $=0.024$ ) was observed in the present study.Similar results were observed by Mutou E [68]. Samathia $\mathrm{P}$ et al showed that $\mathrm{HbA1c}$ can predict the microvascular complications in patients with type 2 diabetes mellitus [69]. A $10 \%$ lower $\mathrm{HbA} 1 \mathrm{c}$ is associated with a $43 \%$ lower risk of retinopathy [70] .Another study by Kamran Mehmood [71] showed an association between higher $\mathrm{HbA1c}$ and progression of retinopathy. The relation between rising $\mathrm{HbA1c}$ levels and coronary artery disease was found to be insignificant (p-value 0.34). As compared with standard therapy, the use of intensive therapy to target normal glycated hemoglobin levels for 3.5 years increased mortality and did not significantly reduce major cardiovascular events in the ACCORD trial [70].There was a highly significant association between increasing duration of diabetes and retinopathy, neuropathy and nephropathy (pvalue <0.001).This was consistent with findings of O.P.Ahuja et al [72] and M.Angelyn Bethel et al [53].However, coronary heart disease had an insignificant association with the duration of diabetes (p-value 0.77) in the present study. 
There is a significant association between treatment modality used and development of diabetic ketoacidosis ( $\mathrm{p}$ value 0.007). However no significant association was found between treatment type and Hyperglycemic Hyperosmolar State (p-value 0.078) or Hypoglycemia (p-value 0.891). In the studied population, most common metabolic complications were Diabetic Ketoacidosis (3.42\%), Hypoglycemia (2.53\%) and Hyperglycemic Hyperosmolar state(1.93\%).Gullermo E Umpierrez et al [73] and Nugent BW [74] showed that the incidence of HHS is lower than DKA and accounts for $<1 \%$ of all primary diabetic admissions.

Out of total admitted patients with diabetes, $8.64 \%$ died (28 males and 30 females).This was in contrast to the findings of Chin Hsiao Tseng [45] where diabetic men have higher risk of dying than women. However similar findings have been reported by JH Fuller et al [75]. Mean age at death was 63.7 years (60.8 years in males and 66.5 years in females) in our study, consistent with the finding of AH Zargar et al [8] and Chin Hsiao Tseng [45] for males but higher age at death in females was seen in their study. Mean HbA1c level among mortalities was $8.31+$ 1.53.It was highest in patients who died of infections (8.47) and lowest in those who died of hypoglycaemia (6.67). More than half of patients died because of infections (60.3\%).This has also been reported by AH Zargar et al [8] ,Wei et al [76] and BB Tripathy et al [48]. However, the results are not in confirmity with the studies of Toshihiko Mihara et al [77] where acute cardiac failure was the leading cause of death and Shelagh I Dawson et al [78] reported same about cardiovascular disease in diabetics. Naveen Krishan Goel et al [79] also observed circulatory diseases as a leading cause of death.Next major cause of death in the present study was strokes (18.9\%).These observations have been reported by AH Zargar et al [8] (13.2\%) also. Renal failure (17.2\%) and myocardial infarction $(12 \%)$ in our study were other causes of mortality. Chronic renal failure contributed to $33.6 \%$ deaths in the study of AH Zargar et al. In his study, coronary artery disease and cerebrovascular disease were responsible for $16.9 \%$ and $13.2 \%$ of deaths respectively [8]. Hypoglycemia was responsible for death in $5.1 \%$ patients in the present study. In the study by AH Zargar et al [8], hypoglycaemia was the cause of death in 3.5\% patients. In the developed world, coronary artery disease and cerebrovascular disease (CVD) are the principal causes of death in diabetics. According to WHO data, CVD and their risk factors are major contributors to global morbidity and mortality [51]. Stroke is reported as a leading cause of disability, second only to dementia [80].

Mean age at death in present study was 63.79 years (60.85 years in males and 66.53 years in females) which is in confirmity with the study by AH Zargar et al [8] in which the mean age of death was 58.76 years, being significantly lower in women than men (57.4 vs 60.1 years, respectively). In a study by Das et al [81] the age at the time of death for people with diabetes was reported to be 55-61 years. Maximum number of patients died of a single cause (48.2\%).43.1\% died of two causes, $6.8 \%$ of three causes and $1.7 \%$ of four or more causes of death. This was consistent with the results by AH Zargar et al [8] showing that death was attributed to a single cause in 392 $(52.9 \%)$, two causes in $269(36.3 \%)$, and three or more causes in $59(8.0 \%)$ cases.

\section{References:-}

1. Duncun C.G. Diseases of Metabolism. W.B.Saunders, Philadelphia, London. Edn 5,1964,pp924. Joslin EP, Root HF, White P \& Marble A. The treatment of diabetes mellitus. Eds Lea \& Febieger, Edn 10 1959,pp11-162.

2. Joslin EP, Root HF, White P \& Marble A. The treatment of diabetes mellitus. Eds Lea \& Febieger, Edn 10 1959,pp11-162.

3. Harris MI,Klein R,Welbom JA, Knuiman MW. Onset of NIDDM occurs at least 4-7 yr before clinical diagnosis.Diabetes Care 1992;15:815-819.

4. Harris MI. Undiagnosed NIDDM:clinical \& public health issues. Diabetes Care 1993;16:642-652.

5. Harris MI,EastmanRC.Early detection of undiagnosed diabetes mellitus: a US perspective.Diabetes Metab Res Rev 2000;16:230-236.

6. Zimmet P, Albert KG, Shaw J. Global and societal implications of the diabetes epidemic.Nature. 2001;414:727787.

7. Shaw JE, Sicree RA, Zimmet PZ. Global estimates of the prevalence of diabetes for 2010 and 2030. Diabetes Res Clin Pract. 2010;87:4-14.

8. H.Zargar et al.Causes of Mortality in diabetes mellitus: data from a tertiary teaching hospital in India.Postgrad Med J 2009;85:227-232.

9. Das AK, Rai N.A world without diabetes \& its complications: A Preventive Programme.In Type 2 diabetes \& its complications: A Preventive Programme.Edn Ist.Microlabs ltd, Bangalore 2008,pp1-15.

10. Adler AI, Stevens RJ, Manley SE, Bilous RW, Cull CA, Holman RR: Development and progression of nephropathy in type 2 diabetes: the United Kingdom Prospective Diabetes Study (UKPDS 64). Kidney Int 63:225 -232, 2003 
11. American Diabetes Association. Clinical practice recommendations 2002.Diabetes Care 2002;25(suppl 1):S1147.

12. Harris MI,Klein R,Welbom JA, Knuiman MW.Onset of NIDDM occurs at least 4-7 yr before clinical diagnosis.Diabetes Care 1992;15:815-819.

13. Almind K,Doria A, Kahn CR.Putting the genes for type II diabetes on the map.Nat Med 2001;7:277-279.

14. Bell GI,Polonsky KS.Diabetes mellitus \& genetically programmed defects in beta cell function.Nature 2001;414:788-791.

15. Thomas A Buchanan, Anny H Xiang.Gestational Diabetes Mellitus.J Clin Invest 2005 March1;115(3):485-491.

16. Fujioka S,Matsuzawa Y,Tokynaga K,Tarui S.Contribution of intra-abdominal fat accumulation to the impairment of glucose \& lipid metabolism in human obesity.Metabolism 1987;36:54-59.

17. Berman DM,Rodriguez LM,Nicklas BJ,et al.Racial disparities in metabolism, central obesity, \&sex hormone binding globulin in postmenopausal women.J Clin Endocrinol Metab 2001;86:97-103.

18. The Expert Committee of the diagnosis \& classification of diabetes mellitus. Report of the Expert Committee on the diagnosis \& classification of diabetes mellitus.Diabetes Care 2011;34(suppl 1):s62-s66.

19. Brambilla P,Manzoni P,Sironi S,et al.Peripheral \& abdominal adiposity in childhood obesity.Int J Obes Relat Metab Disord 1994;18:795-800.

20. Reaven GM.Banting Lecture 1988. Role of insulin resistance in human disease.Nutrition 1997;13:65;discussion 64,66.

21. Reaven GM.Role of insulin resistance in human disease(syndrome X):an expanded definition.Annu Rev Med 1993;44:121-131.

22. The effect of intensive treatment of diabetes on the development \& progression of long term coplications in insulin dependent diabetes mellitus. The Diabetes Control \& Complications Trial Research Group.N Engl J Med 1993;329:977-986.

23. Kuller L H.Stroke \& diabetes.In: National Diabetes Data Group, Eds. Diabetes in America, 2nd Ed. Washington DC: US Department of Health \& Human Services, National Institute of Health, National Institute of Diabetes \& Digestive \& Kidney diesases, 1995.NIH Publication No. 95-1468.pp449-456.

24. Gorina Y, Lentzer H.Multiple causes of death in old age.Hyatts Ville: Aging trends,No. 9.National Centre for Health Statistics, CDC;2008.

25. Scott J,Huskisson EC.Graphic representation of pain.Pain 1976;2:175-186.

26. National Health \& Nutrition Examination Survey(NHANES), National Centre for Health Statistics, CDC \& Prevention, 2005-2008.

27. Ritz E et al.Endstage Renal Failure in Type 2 Diabetes: A Medical Catastrophe of Worldwide Dimension.Am J Kidney dis, 1999;34(5):795-808.

28. UK Prospective Diabetes Study(UKPDS)Group.Tight blood pressure control \& risk of macrovascular \& microvascular complications in type 2 diabetes:UKPDS 38.BMJ 1998;317:703-713.

29. Gregg EW, Sorlie P, Paulose-Ram R et al.Prevalence of lower extremity disease in the US adult population $\geq$ 40 years of age with \& without diabetes: 1999-2000.National Health \& Nutrition Examination Survey.Diabetes Care 2004;27:1591-1597.

30. Zang X, Saaddine JB, Chou CF et al. Prevalence of Diabetic Retinopathy in US 2005-2008.JAMA 2010;304(6:649-656).

31. Brown MJ, Asbury AK: Diabetic Neuropathy.Ann Neurol 1984, 15:2-12.

32. Most RS, Sinnock P.The Epidemiology of lower extremity amputations in diabetic individuals.Diabetes Care $1983 ; 6: 87-91$.

33. Tsai C, Hayes C, Taylor GW.Glycemic control of Type 2 diabetes \& severe periodontal disease in US adult population.Community Dent Oral Epidemiol 2002;30:182-192.

34. Fishbein H, Palumbo PJ.Acute metabolic complications in Diabetes.In: National Diabetes Data Group Eds. Diabetes in America. $2^{\text {nd }}$ Ed. Washington DC.US Department of Health \& Human Services, NIH, NID \& Digestive \& Kidney diseases.NIH Publication 1995,1468(95):283-291.

35. 35.Seaquist ER, Anderson J, Childs B, et al. Hypoglycemia and diabetes: a report of a workgroup of the American Diabetes Association and The Endocrine Society. Diabetes Care. 2013;36(5):1384-1395.

36. Glucose tolerance \& cardiovascular mortality: comparison of fasting \& 2-hour diagnostic criteria.Arch Intern Med 2001;161:397-405.

37. Valdez R, Narayan KM, Geiss LS, Engelgau MM.Impact of diabetes mellitus on mortality associated with pneumonia \& influenza among non-Hispanic black \& white US adults.Am J Public Health 1999;89:1715-1721.

38. Egede LE, Ellis C.Diabetes \& Depression: global perspectives.Diabetes Res Clin Pract 2010;87:302-312. 
39. Grading diabetic retinopathy from stereoscopic color fundus photographs - an extension of the modified Airlie House classification. ETDRS report number 10.Early Treatment Diabetic Retinopathy Study Research Group.Ophthalmology.1991;98:786-806.

40. American Diabetes Association \& American Academy of Neurology.Consensus statement: report \& recommendations of the San Antonio conference on diabetic neuropathy.Diabetes Care 1988;11:592-597

41. Daina Lucia, Suciu Ramona, Chereji Anca, Daina C.Analysis of Morbidity from Diabetes Mellitus in Bihor County.Analele Universitatii din Oradea, Fascicula: Ecotoxicologie, Zootehnie si Tehnologii de Industrie Alimentara 14002011:121-129.

42. Meigs JB.Mittleman MA,Nathan DM,et al.Hyperinsulinemia, hyperglycemia, \& impaired hemostasis.The Framingham Offspring Study.JAMA 2000;283:221-228.

43. Omer MA, Seedat MA, Motala AA, Dyer RB, Becker P.The prevalence of diabetes mellitus \& impaired glucose tolerance in a group of urban South African blacks, S Afr Med J 1993;83(9):641-643.

44. J.C.N.Mbanya, J.Ngogang, J.N.Salah, E.Minkoulou \& B.Balkau.Prevalence of NIDDM \& impaired glucose tolerance in a rural \& an urban population in Cameroon Diabetologia 1997;40:824-829.

45. Chin Hsiao Tseng.Mortality \& Causes of Death in a National Sample of Diabetic Patients in Taiwan.Diabetes Care 2004;27:1605-1609.

46. Eugene Sobngwi, Maimouna Nidour-Mbaye, Kofi A Boateng, et al.Type 2 diabetes control \& complications in specialised diabetes care centres of six sub-Saharan African countries: The Diabcare Africa study.Diabetes Research \& Clinical Practice 2012;95(1):30-36.

47. B Mlacak,Z jaksica,S Vuletica.Albuminuria, Cardiovascular morbidiyu\& mortality in diabetic \& non diabetic subjects in a rural general practice.Family Practice 1999;16(6):580-585.

48. B.B.Tripathy.Proceedings of the Diabetes Update Course, July 27-28,1985.PGIMER,Chandigarh.

49. Raoul M Kamadjeu, Richard Edwards, Joseph S Atanga, Emmanuel C Kiawi, Nigel Unwin \& Jean Claude Mbanya.Anthropometry measures \& prevalence of obesity in the urban adult population of Cameroon: an update from the Cameroon Burden of Diabetes Baseline Survey.BMC Public Health 2006;6:228.

50. Rajendra Pradeepa, Dorairaj Prabhakaran, Viswanathan Mohan.Emerging Economics and Diabetes and Cardiovascular disease.Diabetes Technology and Therapeutics. Volume 14,Supplement 1,2012.

51. World Health Organization: Causes of Death 2008.

52. Alain G Bertoni, Julie S Krop, Gerard F Anderson \& Frederick L Brancati.Diabetes related Morbidity \& Mortality in a National Sample of US Elders.Diabetes Care 2002;25:471-475.

53. M.Angelyn Bethel, Frank A Sloan, Daniel Belsky, Mark N Feinglos.Longitudinal Incidence \& Prevalence of Adverse Outcomes of Diabetes Mellitus in Elderly Patients.Arch Intern Med 2007;167(9):921-927.

54. Colin Berry, Jean Claude Tardif,Martial G Bourassa.Coronary Heart Disease in patients with diabetes.J Am Coll Cardiol 2007;49(6):631-642.

55. Matti Uusitupa,Markku Peltonen,Jaana Lindstrom,Sirkka Aunola.Ten-year mortality \& cardiovascular morbidity in the Finnish Diabetes Prevention Study-Secondary analysis of the Randomised trial.PLOS ONE May 2009;4(5):e5656.

56. M.M.S. Ahuja. Proceedings of the Diabetes Update Course, July 27-28,1985.PGIMER,Chandigarh.

57. Soichi Kurioka, Hiroyuki Ose, Kazuhiro Fukuma, Keisuke Yoshimoto.Severity of diabetic retinopathy is associated with left ventricular diastolic dysfunction in patients with type 2 diabetes.Diabetes Research \& Clinical Practice 2013, Vol 99,Issue 3,Pages 287-291.

58. Upinder K Dhand.Proceedings of the Diabetes Update Course, July 27-28,1985.PGIMER,Chandigarh.

59. Pradeepa R,Rema M,Vignesh J et al. Prevalence and risk factors for diabetic neuropathy in an urban south Indian population: the Chennai Urban Rural Epidemiology Study (CURES-55).Diabet Med,2008Apr 25(4):40712.

60. P.L. Wahi .Proceedings of the Diabetes Update Course, July 27-28,1985.PGIMER,Chandigarh.

61. Gross JL, de Azevedo MJ, Silveiro SP, Canani LH, Caramori ML, Zelmanovitz T: Diabetic nephropathy: diagnosis, prevention, and treatment. Diabetes Care 28: 164-176,2005

62. Chaturvedi N, Bandinelli S, Mangili R, Penno G, Rottiers RE, Fuller JH: Microalbuminuria in type 1 diabetes: rates, risk factors and glycemic threshold. Kidney Int 60: 219-227,2001

63. Centers for Disease Control and Prevention. National diabetes fact sheet: national estimates and general information on diabetes and prediabetes in the United States, 2011. Atlanta, GA: U.S. Department of Health and Human Services, Centers for Disease Control and Prevention, 2011

64. Krowlewski A.S. and Warram J.H.; Epidemiology of late complications of diabetes. In: Joslin's Diabetes Mellitus, 13th ed, Eds Kahn CR and Weir GC; Philadelphia: Lea \& Febiger, 1994; pp 605-619. 
65. Lucia D, Ramona S, Anca C, Daina C.Analysis of Morbidity from diabetes mellitus in Bihor county.Analele Universatii din Oradea, Fascicula: Ecotoxicologie, Zootehnic si Tehnologii de Industrie Alimentara,2011,pp121-130.

66. Andre Pascal Kengne, Albert GB Amoah, Jean Claude Mbanya.Cardiovascular complications of Diabetes Mellitus in sub-Saharan Africa.Circulation 2005;112:3592-3601.

67. Rajendra Pradeepa, Dorairaj Prabhakaran, Viswanathan Mohan.Emerging Economics and Diabetes and Cardiovascular disease.Diabetes Technology and Therapeutics. Volume 14,Supplement 1,2012.

68. Mutou E.The risk of diabetic complications in elderly diabetic patients.Nihon Ronen Iqakkai Zasshi.2012;49(5):597-601.

69. Samathia P,Venkates Warlu M,Siva Prabodh.The Role of Biochemical Markers in the Prediction of Microvascular Complications in Type 2 Diabetes Mellitus.Journal of Clinical \& Diagnostic Research 2011 Nov; $5: 1154-1157$.

70. The relationship of glycemic exposure (HbA1c) to the risk of development and progression of retinopathy in the Diabetes Control and Complications Trial.Diabetes.1995 Aug;44(8):968-83.

71. Kamran Mahmood Ahmad Aziz.Association between High Risk Foot,Retinopathy and HbA1c in Saudi diabetic population.Pak J Physiol 2010;6(2).

72. O. P. Ahuja, Proceedings of the Diabetes Update Course, July 27-28,1985.PGIMER,Chandigarh.

73. Gullermo E Umpierrez ,Mary Beth Murphy, Abbas E Kitabchi.Diabetic Ketoacidosis and Hyperglycemic Hyperosmolar State.Diabetes Spectrum Jan 2002.Vol 15 No.1 28-36.

74. Nugent BW. Hyperosmolar hyperglycemic state. Emerg Med Clin North Am.2005;23:629-648.

75. S.S. Soedamah Muthu, J.H.Fuller, H.E.Mulnier, V.S.Raleigh, R.A.Lawrenson, H.M.Colhoun.All cause mortality rates in patients with type 1 diabetes mellitus compared with a non-diabetic population from the UK general practice research database, 1992-1999.Diabetologia 2006;49:660-666.

76. Wei SY, Shin SJ, Chen JH, et al. Major causes of diabetic death at one hospital.Kao-Hsiung-I-Hsueh-KoHsuch-Tsa-Chin 1996;12:216-20.

77. Toshihiko Mihara,Hiroshi Oohashi,Yukimasa Hirata.Mortality of Japanese diabetics in a seven-year follow-up study.Diabetes Research \& Clinical Practice June 1986,Vol 2,Issue 3,Pages 139-144.

78. Shelagh I Dawson,Jinny Willis,Christopher M Florkowski, Russel S Scott.Cause specific mortality in insulintreated diabetic patients:A 20-year follow-up.Diabetes Research \& ClinicalPractice April 2008,Vol 80, Issue 1,Pages 16-23.

79. Naveen Krishan Goel,SPS Bhatia, Amrit Abrol, Tarun Bhatnagar et al.Changing Mortality Trends in Chandigarh, India. The Internet Journal of Epidemiology 2007. Volume 5 Number 1.

80. Mendis S, Puska P, Norrving B, eds. Global Atlas on Cardiovascular Disease Prevention and Control. World Health Organization, Geneva, 2011.

81. Das S, Mishra RK, Jena BB, et al. Mortality events amongst non-insulin diabetes mellitus patients in Orissa. Journal of the Association of Physicians India 1991;39:519-20. 